\title{
Getting Fuel from Sucrose (Table Sugar)
}

\author{
Al-Baraa Akram \\ Department of Pharmaceutical Biotechnology, De Montfort University, Leicester City, United Kingdom \\ Email: albraaakram94@gmail.com
}

How to cite this paper: Akram, A.-B. (2021) Getting Fuel from Sucrose (Table Sugar). Journal of Sustainable Bioenergy Systems, 11, 272-284.

https://doi.org/10.4236/jsbs.2021.114017

Received: October 15, 2021

Accepted: December 27, 2021

Published: December 30, 2021

Copyright (c) 2021 by author(s) and Scientific Research Publishing Inc. This work is licensed under the Creative Commons Attribution International License (CC BY 4.0).

http://creativecommons.org/licenses/by/4.0/

\begin{abstract}
This idea is based mainly on the most important biochemical process, which is the process of bioremediation, it is based on the use of anaerobic fermentation yeast/Saccharomyces cerevisiae in the conversion of sugar to alcohol and then oxidizing it to get food vinegar followed by some reactions of neutralization and heating using catalysts and increasing pressure to get water gas, or what it is called natural gas. This method produces three liters of natural gas using one liter of sugar solution. The main result of this process is getting 3 folds of natural gas from 1 liter of sugar in addition that the source of biofuel is agricultural so it is free from the organic impurities that are always present with fossil fuels would be obtained and the biofuel obtained does not cause air pollution. Glucose is fermented under anaerobic conditions to avoid the formation of bread yeast.
\end{abstract}

\section{Keywords}

Anaerobic Respiration, Biogas, Saccharomyses ceviseae, Methane, Natural Gas, Gravimetrical Oven, Renewable Energy, Sugar Cane, Sugar Beet

\section{Introduction}

Within the next 25 years. It is expected that world demands for fossil fuels will be increased by $50 \%$ due to the proportionally increased usage of vehicles and instruments which are run by fossil fuel resources like oil, petrol and natural gas despite there is a great progress in modern technology which use alternative sources.

The sources of fossil fuels are not renewable and not pure so, there are adopted strategies and techniques which are alternative to meet the increasing requirements for energy. The anaerobic biodegradation of methane gas was presented in many studies previously, and expectations were ambitious that method will recover energy from fuel reservoirs. Residual oil was found that they could be 
converted to methane gas which is a key component of natural gas, by its biodegradation; producing methane will require inoculation to yield three folds of methane from 1 fold of sugar by concomitant alteration of hydrocarbon and profile and alkane metabolism, sulfate can be used also as an electron acceptor because sulfate is a reducing factor, syntrophic, a fermenting bacteria or yeast can be used for sugar conversion into ethanol.

Collectively, the cells generate methane from a variety of rocks, this source of fuel which is microbial based will be pure and environmental because it doesn't pollute the air and combust efficiently.

It is known that the earth's content of fossil fuel is limited and modern technology innovations are looking for alternative sources of energy. However, the most optimistic expectations say that the alternative sources of fuels will cover only $10 \%$ of world demands by 2030 [1]. Honestly, the demand for fuel will be increased due to the increasing population, the human dependence on fuel for power which is the infrastructure of energy and used widely in factories.

Nowadays, oil recovery techniques can extract only $40 \%$ of fuel that existed on Earth, leaving the rest in mature fields [2]. Developing new technologies may cover fraction of energy consumption and at the same time it will decrease the dependence on the limited sources of energy as well as decrease importing from foreign countries.

Here, it is investigated that possibility to convert methane into a natural gas using hydrocarbon degradation processes is available, usage of bacteria and yeast to convert methane into natural gas is documented in review [3]. Most of these previous studies focus on biodegradation of methane using anaerobic bacteria into natural gas, but this work focuses mainly on getting methane itself from renewable sources like sugar cane which is available and converting it into a biofuel using yeast in anaerobic conditions. For example, most of Earth's reservoirs of fuel have been altered, relying on many factors like water, nutrients, temperature and the required yeast, mainly in absence of oxygen [4].

It was detected that anaerobic metabolites are characterized mainly in polycyclic hydrocarbon aromatic fuels [5]. Detection of many anaerobes, including methanogens, depends on petroleum reservoir fluids [6] [7]. In fact, gasses of biological origin, including methane, are believed to be a by-product of anaerobic oil decomposition [8].

The oil quality resulting from the process above has a low quality due to light consumption. $\mathrm{N}$-alkanes, a major fraction of major oils, has been found that they are degradable under methanogenic conditions, both as pure substrates [9] [10] and the oily mixtures [11] [12], and can be used as sources of methane in biodegraded sources.

Indeed, biodegraded oil reservoirs were combined with anaerobic biodegraded anaerobic processes as a linkage of isotopic fractionation process and modeling of methane with carbon dioxide. In many cases, however, the accumulated methane which is produced biologically was produced long ago; so, producing me- 
thane biologically on human life scale may be not logical or economical enough to be produced sufficiently unless stimulation or inoculation processes have been done [13].

Following methanogenic decay of alkanes, oil entrained could be recovered as natural gas by biodegradation using microorganisms [14], but there is no evaluation of its existence. Here, oil reservoir can be converted into methane hence into natural gas using yeast in anaerobic conditions.

It was found that crude oil can be biodegraded by hydrocarbon-degrading methanogically. Although the various core of tested materials were supplied with nutrients, such as nitrogen and phosphorus salts, carbon dioxide, trace elements and vitamins; methane gas was not obtained without core samples. These requirements for inoculation oil into methane gas processes in mature reservoirs.

It is obvious that there are small fraction of marginal resources of methane can be exploited for methane recovery, so different formations may response to stimulatory techniques rather than inoculation processes. However, an indigenous hydrocarbon degrading isolate can still elusive. This report is a proof of concept that hydrocarbons in reservoir materials can be converted into methane as an alternative source of fuel.

This decomposition requires syntrophic organisms which are able to convert complex substrates into acetate and hydrogen using series of biological reactions. Hydrocarbon degrading consortia are included, similar organisms have been revealed in toluene-degrading enrichment [15]. It was found that oil degrading consortium was derived from river sediment hydrogen/carbon dioxide using unidentified eubacteria. It was proposed that methanogenic oil biodegradation occurs through alkane conversion into acetic acid an hydrogen, with subsequent oxidation of acetic acid to carbon dioxide, coupled with hydrogenotrophic methanogenesis. This theory supported by carbon dioxide isotopic signature, both measured and modeled, suggesting that $\mathrm{CO}_{2}$ reduction to methane predominates in biodegraded reservoirs. It was found that acetate can accumulate relatively to uninhibited inoculations.

Nevertheless, $\mathrm{H}_{2} / \mathrm{CO}_{2}$ based methane production is also a relevant process, but possibly to a lesser extent. The finding of aceticlastic methanogens in the inoculum agrees with the findings of separate investigation, even in the presence of sulfate methanogenesis was the fate of acetate, with $95 \%$ (about 180 out of 190) of the sequenced clones were affiliated with Saccharomyces cerevisiae. It was observed that methane was produced in the presence of $10 \mathrm{mM}$ sulfate in that methanogensis process which uses sulfate as an electron accepting process. It is noted that the microbial population in that study derived from the same gascondensate-contaminated aquifer. The hydrocarbon metabolism varies according to the microorganism used in the process.

Taking the United States as an example, the recovery of energy approximately 1 million barrel of oil per day, which represents about $19 \%$ of the world's production of oil [16]? This percentage can be increased by converting oil into methane, this can be calculated by counting extent of methane could be obtained 
theoretically from reservoirs e.g. 375 billion barrels. For example, taking into consideration measure rete of 0.1 to $0.4 \mu \mathrm{mol}$ methane/day/g, the saturation oil marginal core of the residual oil will be $0.013 \mathrm{~g}$ oil per gram core, and the model density oil will be $0.79 \mathrm{~g} / \mathrm{ml}$ assuming $1 \%$ of residual oil supplies e.g. 3.75 billion barrel would be amenable to biological transformation, the result would be 3 to $13 \mathrm{Bcf}$ of $\mathrm{CH}_{4}$ per day or 1 to $5 \mathrm{Tcf}$ of methane per year, a substantial fraction of natural gas consumption in United States, which is nearing $30 \mathrm{Tcf}$ per year. To simplify this problem, these calculations provide an insight of how an oil transformation into methane process can recover potentially to be economically valuable energy. As it will meet global need for energy [17], conversion of oil into natural gas can occupy a niche in energy production. Obviously, the nutritional and physiological limits (such as temperature limits and pressure) if the described inoculum, it has the ability to migrate through formation, and the engineering design of the bioreactor used will need to be determined.

\section{1) Using natural gas as a fuel for cars}

The use of compressed natural gas for cars began in when car refueling stations used it to serve their buses for transporting the employees.

Natural gas is characterized by its cheaper price compared to other types of fuel such as diesel and gasoline.

As you see in chart below in Figure 1 gasoline and diesel fuel are both in the top three highest prices. Gas costs $\$ 3.37$ and diesel fuel costs $\$ 3.86$. CNG costs $\$ 2.13$, Ethanol costs $\$ 3.14$, and propane costs $\$ 3.08$. The only type of alternative fuel above the price of gas/diesel is biodiesel at $\$ 3.95$. This proves that most types of alternative fuels cost less than gas and diesel fuel. Along with the low cost, most alternative fuels are also better for the environment.

\section{2) Processing and industry}

These projects aim to extract natural gas derivatives of high economic value

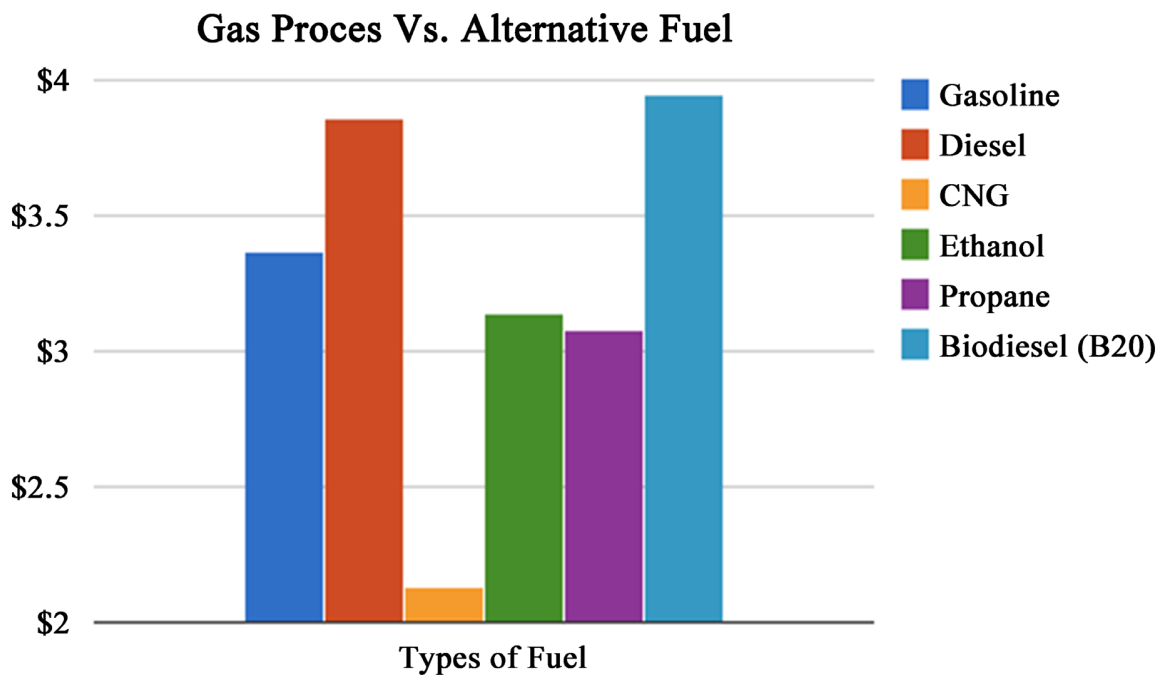

Figure 1. Column chart illustrates the prices in American dollar of gas against different alternative types of fuels such as gasoline, diesel, CNG, ethanol, propane and biodiesel.

by processing natural gas to produce propane in order to reduce its import from 
abroad.

The ethane/propane mixture is used as a feedstock for the production of ethylene, the main material in petrochemical production, which in turn produces ethylene used in the manufacture of polyethylene, which is used in the plastics industry.

Temperature plays an important role in each stage of fuel extracting. As shown in Figure 2 Different stages of oil heating and its melting or evaporating point extracts a specific type of fuel e.g. in temperature less than $25^{\circ} \mathrm{C}$ petroleum gas is obtained, in temperature from $60^{\circ} \mathrm{C}$ to $180^{\circ} \mathrm{C}$ naphtha is obtained, in temperature between $180^{\circ} \mathrm{C}$ to $220^{\circ} \mathrm{C}$ paraffin is obtained, in temperature from $220^{\circ} \mathrm{C}$ to $250^{\circ} \mathrm{C}$ diesel is obtained, in temperature between $250^{\circ} \mathrm{C}$ to $300^{\circ} \mathrm{C}$ fuel oil is obtained, in temperature between $300^{\circ} \mathrm{C}$ to $350^{\circ} \mathrm{C}$ lubricating oil is obtained and in temperature more than $350^{\circ} \mathrm{C}$ bitumen is obtained.

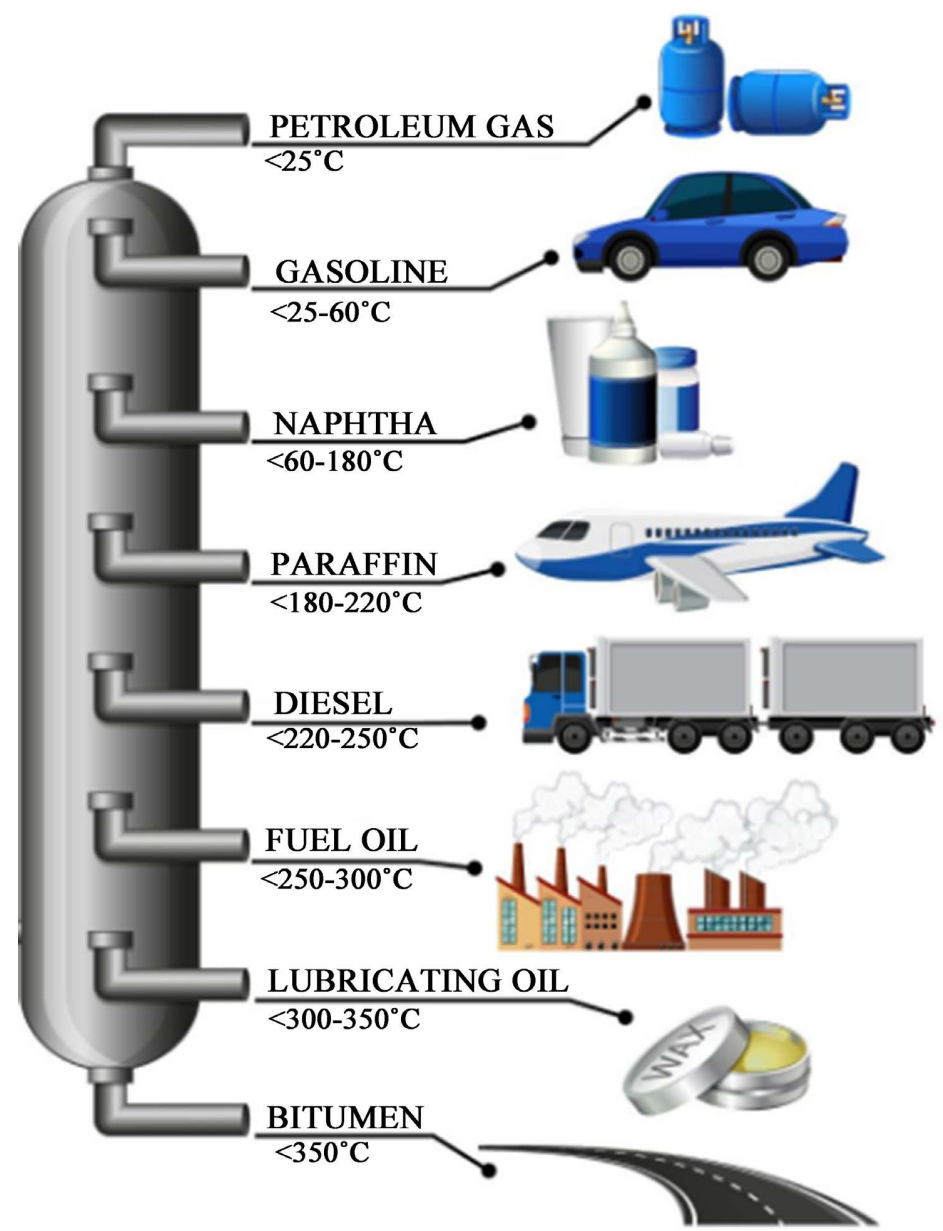

Figure 2. Different stages of oil heating and its melting or evaporating temperatures in each stage illustrating the applications of every output e.g. in temperature less than $25^{\circ} \mathrm{C}$ petroleum gas is obtained, in temperature from $60^{\circ} \mathrm{C}$ to $180^{\circ} \mathrm{C}$ naphtha is obtained, in temperature between $180^{\circ} \mathrm{C}$ to $220^{\circ} \mathrm{C}$ paraffin is obtained, in temperature from $220^{\circ} \mathrm{C}$ to $250^{\circ} \mathrm{C}$ diesel is obtained, in temperature between $250^{\circ} \mathrm{C}$ to $300^{\circ} \mathrm{C}$ fuel oil is obtained, in temperature between $300^{\circ} \mathrm{C}$ to $350^{\circ} \mathrm{C}$ lubricating oil is obtained and in temperature more than $350^{\circ} \mathrm{C}$ bitumen is obtained. 


\section{Materials and Methods}

It is known that sucrose is extracted from sugar cane plant or sugar beet, so to get natural gas from sugar follow these steps.

1) Sucrose is processed with enzyme called invertase or sucrose to convert sucrose into glucose and fructose according the equation below

$$
\mathrm{C}_{12} \mathrm{H}_{22} \mathrm{O}_{11}+\text { invertase } \rightarrow \mathrm{C}_{6} \mathrm{H}_{12} \mathrm{O}_{6}+\mathrm{C}_{6} \mathrm{H}_{12} \mathrm{O}_{6}
$$

Sucrose + invertase $\rightarrow$ glucose + fructose

As shown in Figure 3 structure of precursor sucrose in space consists of twelve carbon atoms, twenty two hydrogen atoms and eleven oxygen atoms.

2) Ferment glucose in anaerobic conditions using anaerobic respiration microbe called Saccharomyces cerevisiae in the presence of zymase enzyme as a catalyst to obtain ethanol or ethyl alcohol according to the equation below

$$
\mathrm{C}_{6} \mathrm{H}_{12} \mathrm{O}_{6}+\mathrm{H}_{2} \mathrm{O} \rightarrow \mathrm{C}_{2} \mathrm{H}_{5} \mathrm{OH}+\mathrm{CO}_{2}
$$

Glucose + zymase/Saccharomyces cerevisiae (anaerobic) $\rightarrow$ ethanol

Structure of zymase enzyme is shown in Figure 4 which is an enzyme complex that catalyzes the fermentation of sugar into ethanol and carbon dioxide. It occurs in nature mainly in yeasts and varies according to yeast strains.

3) Oxidize ethanol using potassium dichromate acidified with concentrated sulfuric acid to get a less stable compound which is acetaldehyde or ethanal which is quickly and spontaneously oxidized to produce acetic acid or vinegar according to the equation below

$$
\mathrm{C}_{2} \mathrm{H}_{5} \mathrm{OH}+\mathrm{K}_{2} \mathrm{Cr}_{2} \mathrm{O}_{7}+\mathrm{H}_{2} \mathrm{SO}_{4} \rightarrow \mathrm{CH}_{3} \mathrm{CHO}+(\mathrm{O}) \rightarrow \mathrm{CH}_{3} \mathrm{COOH}
$$

Ethanol + Potassium Dichromate + Sulphoric acid (Conc.) $\rightarrow$ Acetaldehyde $\rightarrow$ Acetic acid

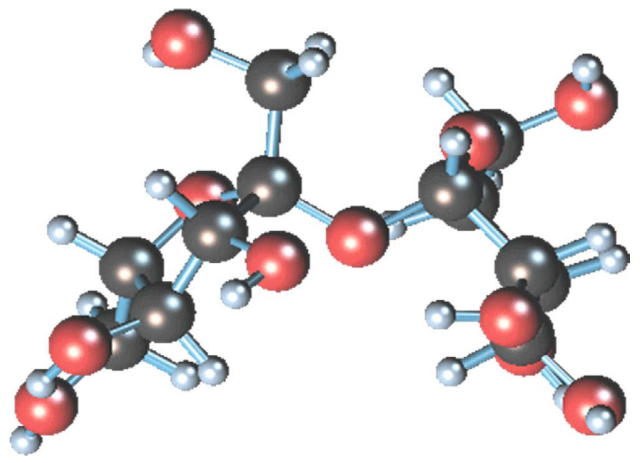

Figure 3. Structure of precursor sucrose in space consists of twelve carbon atoms, twenty two hydrogen atoms and eleven oxygen atoms.
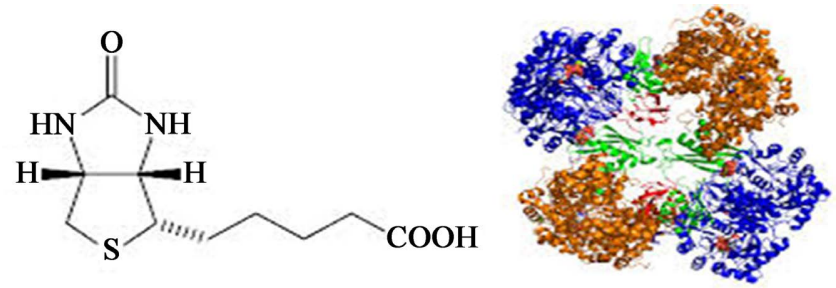

Figure 4. Structure of zymase enzyme. 
4) In a neutralization reaction, neutralize acetic acid with sodium hydroxide to get sodium acetate and water according to the equation below

$$
\mathrm{CH}_{3} \mathrm{COOH}+\mathrm{NaOH} \rightarrow \mathrm{CH}_{3} \mathrm{COONa}+\mathrm{H}_{2} \mathrm{O}
$$

Acetic acid + Sodium hydroxide $\rightarrow$ Sodium Acetate + water

5) The resulted sodium acetate is reacted with soda lime (a mixture of sodium hydroxide and calcium oxide for the sake of reducing the melting point in the reaction) with heating in Bunsen flame to obtain methane and sodium carbonate as shown in Figure 5. Precaution in this step; the tip of the tube must be downwards because the resulting methane gas is light and volatile according to the equation below

$$
\mathrm{CH}_{3} \mathrm{COONa}+\mathrm{NaOH}+\mathrm{CaO}+\text { Heat } \rightarrow \mathrm{CH}_{4}+\mathrm{Na}_{2} \mathrm{CO}_{3}
$$

$$
\text { Sodium Acetate }+ \text { Soda lime } \rightarrow \text { Methane }+ \text { Sodium Bicarbonate }
$$

6) Finally, methane gas is reacted with hot water at a temperature of $725^{\circ} \mathrm{C}$ using a gravimetrical oven (the temperature can be controlled up to $900^{\circ} \mathrm{C}$ ) and the pressure is increased to 200 atmospheric pressure as shown in Figure 6 to form a mixture of hydrogen gas and carbon monoxide which are combined rapidly after the reaction to produce hydro-gas or natural gas which is an efficient fuel according to the illustrated equation below

$$
\mathrm{CH}_{4}+\mathrm{H}_{2} \mathrm{O}+\text { Heat } \rightarrow 3 \mathrm{H}_{2} \mathrm{CO}
$$

Methane + water + Catalyst $\rightarrow$ Natural gas

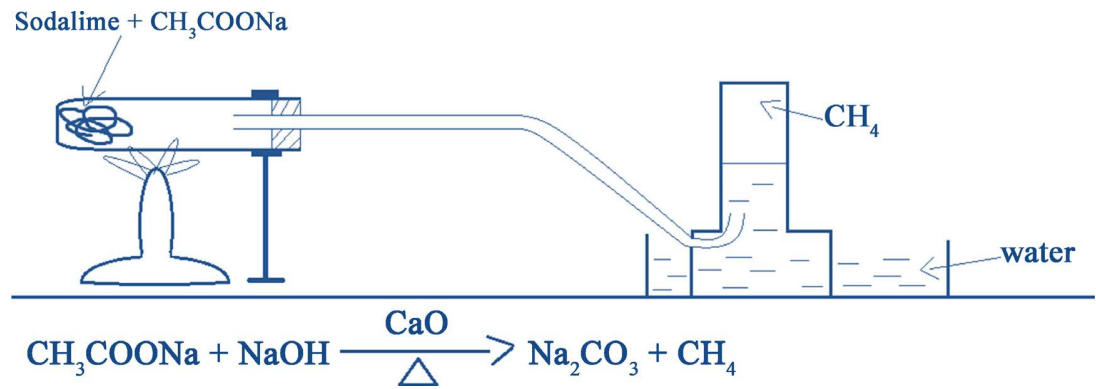

Figure 5. Reaction between soda lime and sodium acetate to form methane, the tip of the tube is downwards (on the right) to prevent evaporation and volatilization of resulted methane and put in cold water sank to decrease the reaction temperature.

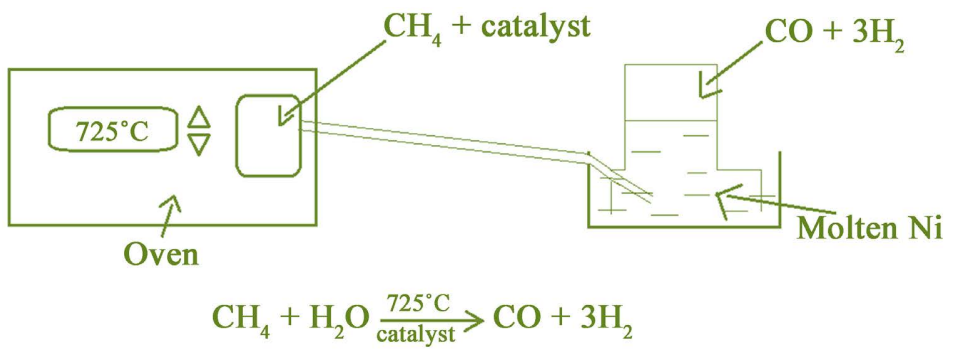

Figure 6. Reaction of methane with water to produce natural gas, the temperature in the gravimetrical oven is adapted to $725^{\circ} \mathrm{C}$ in the presence of a catalyst and increasing pressure. The tube in the right should be also pointed outwards in water sank to decrease the reaction temperature and facilitate gas collection. 


\section{Results}

The most important feedback of this process is getting fuel more than the amount of given sugar, as the equation started with 1 mole of sucrose and ends with getting 3 moles of natural gas. In practice, the net result of the process is 3 liters of natural gas for each 1 liter of sucrose solution. This can solve the problem of fuel proportionally.

Biofuel can be more efficient than the fossil fuel. Engineering sugarcane, which is the most productive plant in the world, produces natural gas by this method. In this study, it was found that sugarcane is able to yield 2500 liters of biofuel per acre of land. Sugarcane wastes could be recycled and used as a biofuel as a recycling project as shown in Figure 7.

In simple terms, this means that a Boeing 747 plane can fly for 10 hours using biofuel produced from 54 acres of land. Comparing between many plant sources produce biofuels, sugar cane can produce about 13 to 15 times of biofuel per unit of agricultural land.

However, even after scientific research and commercial efforts, current production volumes of biofuels are very small. Making these products need to be done on a larger scale and need more advance technology and low cost crops.

Sugarcane and sugar beet are both proposed to produce biofuel rather than natural gas. For instance, sugar cane contains about $0.05 \%$ oil which can be used to produce biodiesel. Some researchers theorize that $1 \%$ of oil in the plant can be toxic to the plant itself. But computer models theorize that oil content can be increased to reach $20 \%$.

These plants can be modified genetically to replace fossil fuels. Genetic modification can increase oil production in the plant to reach $12 \%$ in the leaves of

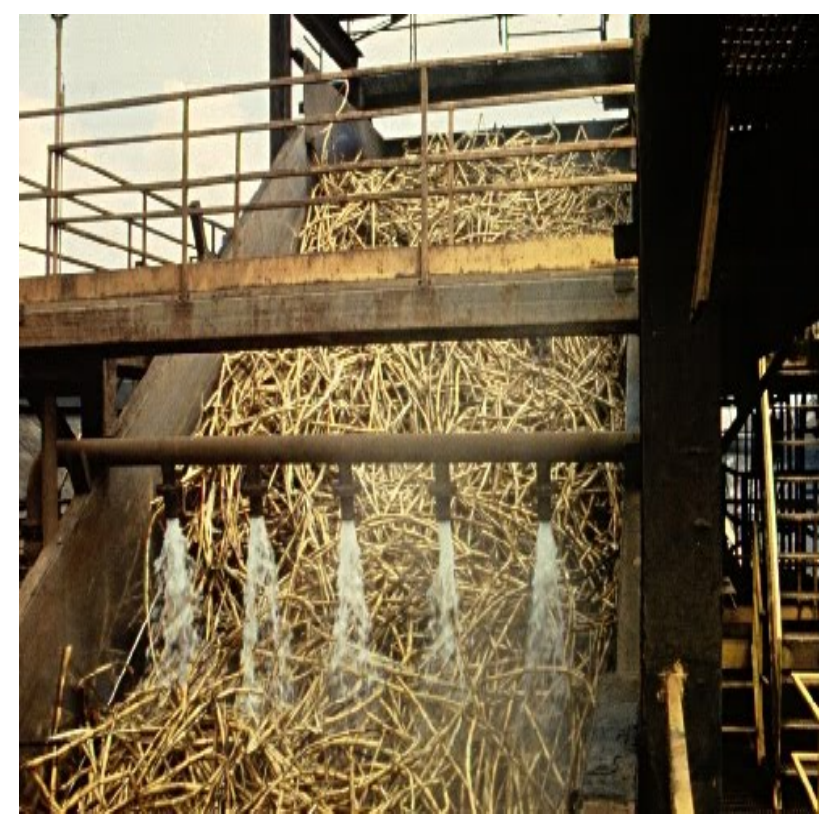

Figure 7. Application of extracting sugar from sugarcane wastes to be used as a biofuel as a recycling project. 
sugarcane. To be sustainable, biofuel must not be expensive and high yield to avoid use fossil fuel which are impure and pollutants. Sugar cane can produce $20 \%$ of oil per acre.

Sugar cane provides also a commercial benefit related to energy, the plant parts left after juice extraction, known as bagasse, can be burned to produce steam and electricity. According to those analyses, this can generate electricity to empower the factories, so the surplus power could be sold back to the grid, displacing electricity produced from fossil fuels.

Sugar cane plant should be engineered to be cold tolerant especially in cold countries to be grown widely. Figure 8 shows suitable places for sugarcane agriculture in United States. Grey marks represent land which are used currently for food crops, yellow marks for marginal land available for modified sugarcane, light green marks represent places where modified sugarcane will be able to grow in the future and deep green marks represent lands where sugar cane is currently growing.

Presently, in current dollars, this fuel will cost airline about 5.13\$ per gallon which is less than other biofuels extracted from algae or other crops like palm oil. Sugarcane can be grown in tropical countries in South America and Africa. Growing of sugarcane in Brazil for example can reduce carbon dioxide emission by $5.6 \%$.

Now, sugarcane can be modified to produce biodiesel and bio-jet fuel in addition to natural oil production.

\section{Discussion}

Single stage anaerobic conversion of sugar cane into natural gas is considered as the cheapest method to get fossil fuel using a laboratory and chemical methods

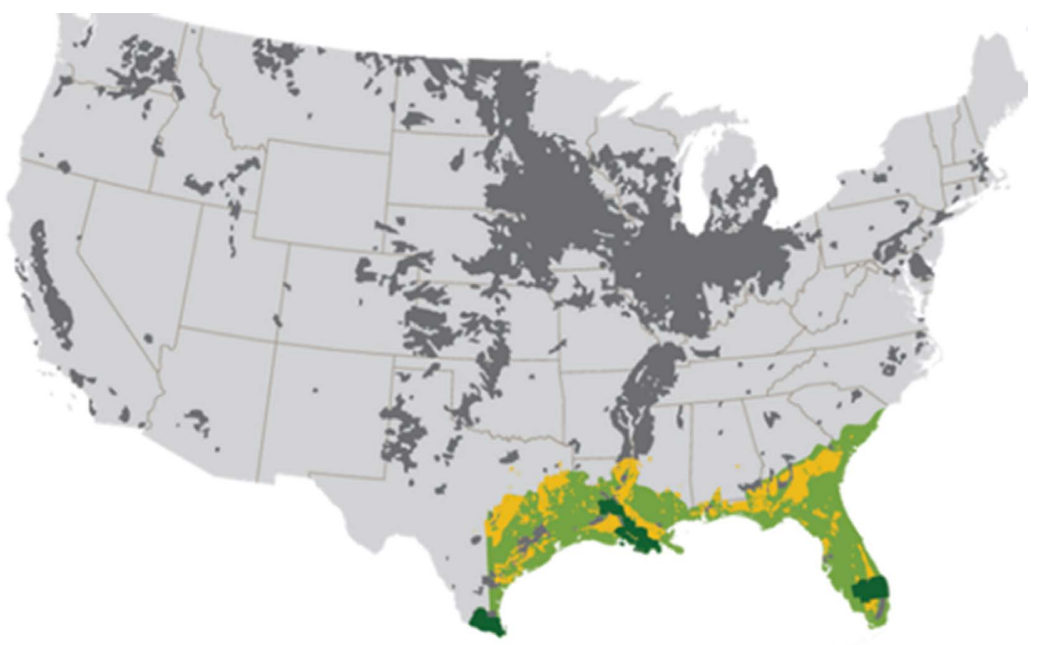

Figure 8. Suitable places for sugarcane agriculture in United States. Grey marks represent land which are used currently for food crops, yellow marks for marginal land available for modified sugarcane, light green marks represent places where modified sugarcane will be able to grow in the future and deep green marks represent lands where sugar cane is currently growing. 
in these experiment. Sugar cane has a low $\mathrm{pH}$ reaches 3.3. This experiment can be developed to be performed in a bioreactor in factories to produce this gas on a large scale. The reactor is done using hydraulic retention time range between 15 and 95 days. And an organic loading rate between 0.9 and $6.3 \mathrm{~g}^{-1} \cdot \mathrm{VSl}^{-1} \cdot \mathrm{d}^{-1}$.

The highest gas specific production rate can raech $0.72 \mathrm{~g}^{-1} \cdot \mathrm{VSl}^{-1} \cdot \mathrm{d}^{-1}$ could be produced with 25 days of hydraulic reaction time with an average methane content of $63 \%$, at a pH around 6.8 which is slightly neutral. Sugar cane itself is weak substrate, talking about the nutrients and capacity of the buffer in the bioreactor, regulr nitrogen sublementation will be performed for the sake of obtaining stable process. Sodium or ptassium carbonate resulted from the reaction No. 5 plays a significant role in these processes, among the other agents used, to maintain buffering capacity and stabilize $\mathrm{pH}$.

Usage of a new harvest (a new charge of a substrate) also affects the specific gas production rate values significantly.

In Figure 9 below, the bioreactor is supplied with a motor and impeller to stir the harvest, magesium oxide can be used as an antifoaming agent to guarantee reaction process in an anaerobic condition, two steam exits are put up and down of the bioreactor to remove resulted unnecessary gasses, nutrient and inoculent inlet to provide the necessary substances to yeast, nutrient medium should be sterile to avoid any impurities, probes should be processed in the bioreactor which will be oxygen probe to measure oxygen concentration, $\mathrm{pH}$ probe to guarantee the a $\mathrm{pH}$ at 6.8 as well as temperature probe to adapt the reaction temperature. Also the bioreactor is put inside a cooling jacket to insulate it from the surrounding heat and to reduce the reaction temperature, cold water inlet is added if temperature probe recorded a high temperature, acid/base inlet is put to

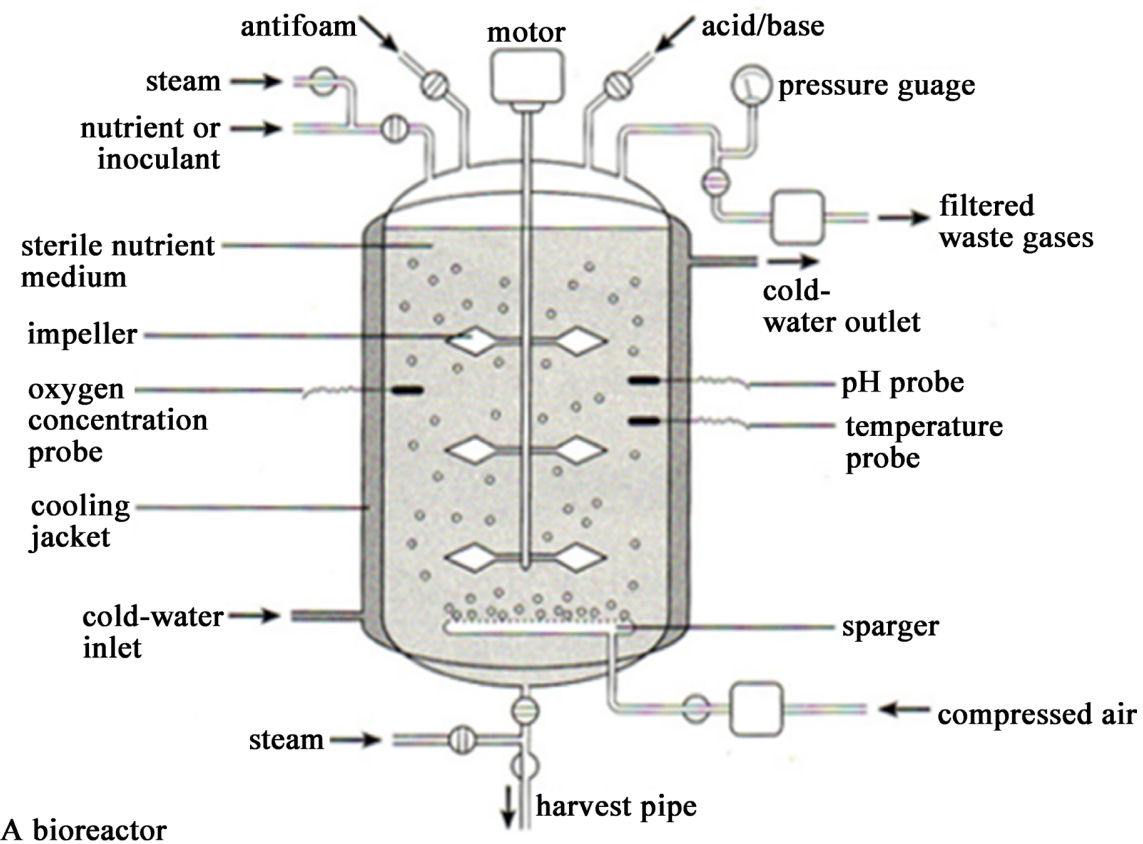

A bioreactor

Figure 9. Future bioreactor which will be used to produce natural gas from sugar. 
adapt the acidity of the reacion according to the records of $\mathrm{PH}$ probe, pressure guage is put to control the pressure and adapt it. Filter waste gases is added to get rid of the impure gasses, cold water outlet is put to remove the water which is necessary only to maintain reaction temperature. Finally harvest pipe is put to collect natural gas and load it into the target markets.

The present fuel crisis brings attention to biogas to be used as an alternative. Energy source is economically feasible and unlimited in potentials. Moreover, the economy of biogas plants can be improved by adding substrates from bacteria and yeast. One such substrate was identified, having high nitrogen and phosphate content, to amend biogas produced from microorganisms. This is almost 63.4\% increase in biogas production compared with the traditional gas extraction rate from fossil fuels which can reach $2089 \mathrm{ml}$ per day for each experiment. Capillary suction time is maintained between 320 to 394 seconds.

Although first generation biofuels are prepared from nutrient sources, the second generation can be prepared from non-edible sources of biofuels such as agricultural wastes and cellulose substrates as Figure 10 illustrates sources and yields of petrochemicals naturally and artificially. Moreover, the investigation of third generation of fuels made from algae has been started. Thus, increase in food supply to compete with the rapid increasing in world population is a great challenge leads researchers to prefer second and third generation biofuels.

\section{Conclusions}

The result of this experiment is to get 3 liters of natural gas from 1 liter of sucrose in addition to that a source of vegetable fuel free from the organic impurities that are always present with fossil fuels would be obtained. Glucose is fermented under anaerobic conditions to avoid the formation of bread yeast.

The use of soda lime (a mixture of sodium hydroxide and calcium oxide to reduce the melting point in the reaction) with heating to obtain methane gas. In this experiment, the tip of the tube must be downwards because the resulting methane gas is a light and volatile gas and the tube itself should be pointed to a cold water sank to decrease the temperature of reaction as this reaction is exothermic.

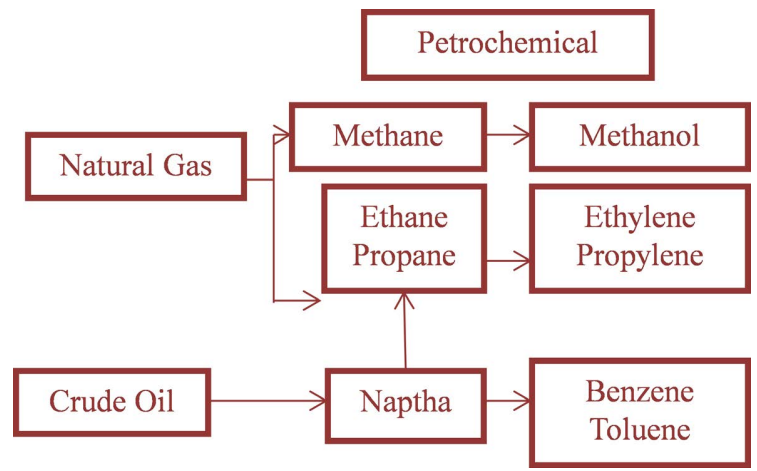

Figure 10. Scheme illustrates sources and yields of petrochemicals naturally and artificially. 
Methane is prepared in a bath of cold water to lower the reaction temperature. Methane gas is reacted with hot water at a temperature of $725^{\circ} \mathrm{C}$ using a Gravimetrical oven (the temperature can be controlled to $900^{\circ} \mathrm{C}$ ) and using a catalyst (heated nickel to reddening) and the pressure is increased to $200 \mathrm{~atm}$.

The future work can be based on getting fuels from other sources of sugars like milk and malt which can produce more quantity and higher quality of fuels.

\section{Acknowledgements}

Very big thanks to Dr. Somia M.Al-Ghazaly/master student in faculty of pharmacy-Cairo University-Department of industrial pharmacy: for her assistance in designing figures manually, reading, revising and organizing this manuscript, making me laugh when I stopped believing it was any good, and for being the chess queen to my chess king within these many, many months.

\section{Conflicts of Interest}

The author declares no conflicts of interest regarding the publication of this paper.

\section{References}

[1] Energy Information Administration (2007) Annual Energy Outlook. DOE/EIA-0383. U.S. Department of Energy, Washington DC.

https://www.sciencedirect.com/science/article/abs/pii/S0301421509000755

[2] U.S Department of Energy (2006) Undeveloped Domestic Oil Resources: The Foundation for Increasing Oil Production and a Viable Domestic Oil Industry. www.fossil.energy.gov/program/oilgas/eor/undeveloped_Domestic_Oil_Resources provi.html

[3] Widdel, F., Boetius, A. and Rabus, R. (2006) Anaerobic Biodegradation of Hydrocarbons Including Methane. In: Dworkin, M., Falkow, S., Rosenberg, E., Schleifer, K.H. and Stackebrandt, E., Eds., The Prokaryotes: Ecophysiology and Biochemistry, Springer-Verlag, New York, 1028-1049. https://doi.org/10.1007/0-387-30742-7_33

[4] Head, I.M., Jones, D.M. and Larter, S.R. (2003) Biological Activity in the Deep Subsurface and the Origin of Heavy Oil. Nature, 426, 344-352.

https://doi.org/10.1038/nature02134 https://www.researchgate.net/publication/8999662_Head_IM_Jones_DM_Larter_S $\underline{\text { R_Biological_activity_in_the_deep_subsurface_and_the_origin_of_heavy_oil_Natu }}$ re_426_344-352

[5] Aitken, C.M., Jones, D.M. and Larter, S.R. (2004) Anaerobic Hydrocarbon Biodegradation in Deep Subsurface Oil Reservoirs. Nature, 431, 291-294. https://doi.org/10.1038/nature02922

[6] Magot, M. (2005) Indigenous Microbial Communities in Oil Fields. In: Ollivier, B. and Magot, M., Eds., Petroleum Microbiology, ASM Press, Washington DC, 21-33. https://doi.org/10.1128/9781555817589.ch2 https://link.springer.com/referenceworkentry/10.1007\%2F978-3-540-77587-4_156

[7] Nazina, T.N., Shestakova, N.M., Grigor'yan, A.A., Mikhailova, E.M., Tourova, T.P., Poltaraus, A.B., Feng, C., Ni, F. and Belyaev, S.S. (2006) Phylogenetic Diversity and Activity of Anaerobic Microorganisms of High-Temperature Horizons of the Da- 
gang Oil Field (P. R. China). Microbiology, 75, 55-65.

https://doi.org/10.1134/S0026261706010115

[8] Pallasser, R.J. (2000) Recognising Biodegradation in Gas/Oil Accumulations through the $\partial^{13} \mathrm{C}$ Composition of Gas Components. Organic Geochemistry, 31, 1363-1373. https://doi.org/10.1016/S0146-6380(00)00101-7

[9] Anderson, R.T. and Lovley, D.R. (2000) Hexadecane Decay by Methanogenesis. Nature, 404, 722-723. https://doi.org/10.1038/35008145

[10] Zengler, K., Richnow, H.H., Rossello-Mora, R., Michaelis, W. and Widdel, F. (1999) Methane Formation from Long-Chain Alkanes by Anaerobic Microorganisms. Nature, 401, 266-269. https://doi.org/10.1038/45777

[11] Jones, D.M., Head, I.M., Gray, N.D., Adams, J.J., Rowan, A.K., Aitken, C.M., Bennett, B., Huang, H., Brown, A., Bowler, B.F.J., Oldenburg, T., Erdmann, M. and Larter, S.R. (2008) Crude-Oil Biodegradation via Methanogenesis in Subsurface Petroleum Reservoirs. Nature, 451, 176-180. https://doi.org/10.1038/nature06484

[12] Siddique, T., Fedorak, P.M. and Foght, J.M. (2006) Biodegradation of Short-Chain $n$-Alkanes in Oil Sands Tailings under Methanogenic Conditions. Environmental Science \& Technology, 40, 5459-5464. https://doi.org/10.1021/es060993m

[13] Townsend, G.T., Prince, R.C. and Suflita, J.M. (2003) Anaerobic Oxidation of Crude Oil Hydrocarbons by the Resident Microorganisms of a Contaminated Anoxic Aquifer. Environmental Science \& Technology, 37, 5213-5218. https://doi.org/10.1021/es0264495

[14] Parkes, J. (1999) Cracking Anaerobic Bacteria. Nature, 401, 217-218. https://doi.org/10.1038/45686

[15] Ficker, M., Krastel, K., Orlicky, S. and Edwards, E. (1999) Molecular Characterization of a Toluene-Degrading Methanogenic Consortium. Applied and Environmental Microbiology, 65, 5576-5585.

[16] Office of Fossil Energy and Carbon Management. www.fossil.energy.gov/programs/oilgas/marginalwells/index.html

[17] Whitesides, G.M. and Crabtree, G.W. (2007) Don't Forget Long-Term Fundamental Research in Energy. Nature, 315, 796-798. https://doi.org/10.1126/science.1140362 